Jurnal Qua Teknika, Vol. 8 No. 2 September 2018

p-ISSN: 2088-2424; e-ISSN: 2527-3892

Fakultas Teknik Universitas Islam Balitar, Blitar

Http://qua.unisbablitar.ejournal.web.id; Email; quateknika@Gmail.com

Hazairin Nikmatul L, Deddy Setyawan, Chosinawarotin. 2018. Rancang Bangun Media Animasi Pictorial Riddle sebagai Media Pembelajaran Fisika Bangunan Mahasiswa Teknik Sipil Jurnal Qua Teknika, (2018), 8(2) : 53-61

\title{
RANCANG BANGUN MEDIA ANIMASI PICTORIAL RIDDLE SEBAGAI MEDIA PEMBELAJARAN FISIKA BANGUNAN MAHASISWA TEKNIK SIPIL
}

\author{
Hazairin Nikmatul L ${ }^{1)}$, Deddy Setyawan, Chosinawarotin \\ Program Studi Teknik Sipil, Fakultas Teknik, Universitas Islam Balitar \\ Jl. Mojopahit No. 4 Kota Blitar Jawa Timur \\ ${ }^{1}$ Email : haza.airin@gmail.com
}

\begin{abstract}
ABSTRAK
Penelitian ini bertujuan untuk mendesain sebuah media pembelajaran yang bersifat menarik, kreatif, serta interaktif dalam sebuah proses pembelajaran, pada Mata Kuliah Fisika Bangunan Program Studi Teknik Sipil Fakultas Teknik Universitas Islam Balitar Blitar. Desain Media Pembelajaran merupakan tampilan animasi, dengan aplikasi Software Adobe Flash Player 8, dengan metode pembelajaran yang diterapkan adalah Pictorial Riddle. Penelitian menggunakan metode kuasi eksperimen dengan desain one group pretest-posttest design. Sampel penelitian diambil secara acak dari seluruh mahasiswa yang memprogram mata kuliah Fisika Bangunan, sebanyak 20 orang. Peningkatan tes hasil belajar mahasiswa dianalisis menggunakan N-gain. Hasil penelitian menunjukkan bahwa penerapan media animasi Pictorial Riddle dapat meningkatkan hasil belajar mahasiswa pada mata kuliah Fisika Bangunan, pada pertemuan pertama sebesar $17 \%$ dengan N-gain sebesar 0,40 dan masuk dalam kategori sedang. Sedangkan pada pertemuan kedua terjadi peningkatan sebesar $11 \%$ dengan $\mathrm{N}$ gain sebesar 0,35, masuk dalam kategori sedang.
\end{abstract}

Kata kunci: media pembelajaran, animasi, pictorial riddle, fisika bangunan

\section{ABSTRACT}

This research aims to design a learning media that is interesting, creative, and interactive in a learning process, in the Building Physics Course in the Civil Engineering Study Program, Faculty of Engineering, Blitar Balitar Islamic University. Learning Media Design is an animated display, with Adobe Flash Player 8 Software application, with the learning method applied is Pictorial Riddle. The study used a quasi-experimental method with the design of one group pretest-posttest design. The research sample was taken randomly from all students who programed the Building Physics course, as many as 20 people. Improved student learning outcomes tests were analyzed using $N$-gain. The results showed that the application of Pictorial Riddle animation media can improve student learning outcomes in the Building Physics course, at the first meeting of $18 \%$ with $N$-gain of 0.40 and in the medium category. While in the second meeting there was an increase of $12 \%$ with $N$-gain of 0.35 , included in the medium category.

Keywords : learning media, animation, pictorial riddle, building physics

\section{PENDAHULUAN}

Sesuai dengan Undang-Undang Republik Indonesia nomor 20 tahun 2003 tentang Sistem Pendidikan Nasional, disebutkan bahwa pendidikan nasional memiliki peran yang sangat penting yang pada akhirnya akan menentukan masa depan sebuah bangsa. Pendidikan nasional disini mencakup mulai dari pendidikan dasar, pendidikan menengah, hingga pendidikan tinggi.

Dalam rangkaian proses pendidikan, termasuk dalam tingkat pendidikan tinggi, tercakup unsur di dalamnya yaitu pembelajaran. Pembelajaran yang efektif adalah pembelajaran yang bermakna dimana pembelajaran dikembangkan dengan membantu siswa membangun keterkaitan antara informasi baru dengan pengetahuan atau pengalaman yang telah dimiliki mahasiswa. Dan antara mahasiswa sebagai peserta didik dan dosen sebagai penyedia informasi, harus terdapat interaksi yang berlangsung dua arah di antara keduanya.

Dalam upaya untuk memberikan penguasaan konsep terhadap mahasiswa, seorang dosen alangkah baiknya mampu menguasai beragam metode, model, ataupun teknologi pembelajaran. Hal ini dikarenakan, untuk menciptakan suasana pembelajaran yang menyenangkan, seorang dosen tidak bisa hanya berkutat pada satu metode, atau satu model, ataupun satu media pembelajaran saja. Terlebih untuk Mata Kuliah Fisika Bangunan, salah satu Mata Kuliah wajib bagi mahasiswa teknik sipil. Perlu pemahaman yang mendalam mengenai konsepkonsepnya. Tentunya pilihan metode yang menarik harus ditentukan, agar mahasiswa dapat memahami dengan baik mengenai mata kuliah ini. 
Jurnal Qua Teknika, Vol. 8 No. 2 September 2018

p-ISSN: 2088-2424; e-ISSN: 2527-3892

Fakultas Teknik Universitas Islam Balitar, Blitar

Http://qua.unisbablitar.ejournal.web.id; Email; quateknika@Gmail.com

Hazairin Nikmatul L, Deddy Setyawan, Chosinawarotin. 2018. Rancang Bangun Media Animasi Pictorial Riddle sebagai Media Pembelajaran Fisika Bangunan Mahasiswa Teknik Sipil

Jurnal Qua Teknika, (2018), 8(2) : 53-61

Dengan dilatarbelakangi paparan di atas, maka dilakukan penelitian ini, yaitu merancang sebuah media pembelajaran yang bersifat interaktif, dimana metode pembelajaran yang dipilih adalah Pictorial Riddle, dengan media pembelajaran berupa animasi. Penelitian ini bertujuan untuk mengetahui sejauh mana pengaruh penerapan metode animasi dari Pictorial Riddle.

\section{Media Pembelajaran}

Secara umum, media adalah setiap orang, bahan, alat, atau peristiwa yang dapat menciptakan kondisi yang memungkinkan siswa untuk menerima pengetahuan, keterampilan, dan sikap. Dengan demikian, guru atau dosen, buku ajar, lingkungan adalah media. Setiap media merupakan sarana untuk menuju ke suatu tujuan. Di dalamnya terkandung informasi yang dapat dikomunikasikan kepada orang lain (Sri Anitah, 2007:3). Dalam pembelajaran, media memiliki peran sebagai penyalur pesan atau penyalur informasi untuk mencapai tujuan pembelajaran.

Masih menurut Sri Anitah (2007:55-56) pemilihan media yang terbaik untuk tujuan pembelajaran tertentu bukanlah hal yang mudah. Tetapi bagaimanapun juga seorang guru harus dapat menentukan media yang paling tepat dalam melaksanakan kegiatan pembelajaran. Dalam pemilihan media, Gagne dkk (1988) menyarankan perlunya mempertimbangkan beberapa variabel, diantaranya variabel tugas. Dalam pemilihan media, guru harus menentukan jenis kemampuan yang diharapkan dari siswa sebagai hasil pembelajaran, dan disarankan untuk menentukan jenis stimulus yang diinginkan sebelum melakukan pemilihan media

\section{Animasi}

Definisi animasi sendiri berasal dari kata 'to animate' yang berarti menggerakkan atau menghidupkan. Misalkan sebuah benda yang mati, lalu digerakkan melalui perubahan sedikit demi sedikit dan teratur sehingga memberikan kesan hidup. Animasi adalah proses penciptaan efek gerak atau efek perubahan bentuk yang terjadi selama beberapa waktu. Animasi juga merupakan suatu teknik menampilkan gambar berurut sedemikian rupa sehingga penonton merasakan adanya ilustrasi gerakan (motion) pada gambar yang ditampilkan. Animasi dalam pembelajaran fisika merupakan program pembelajaran yang menarik, menghibur, dan menyenangkan yang ditampilkan dalam komputer dalam bentuk gambar bergerak agar siswa dapat memahami konsep fisika.

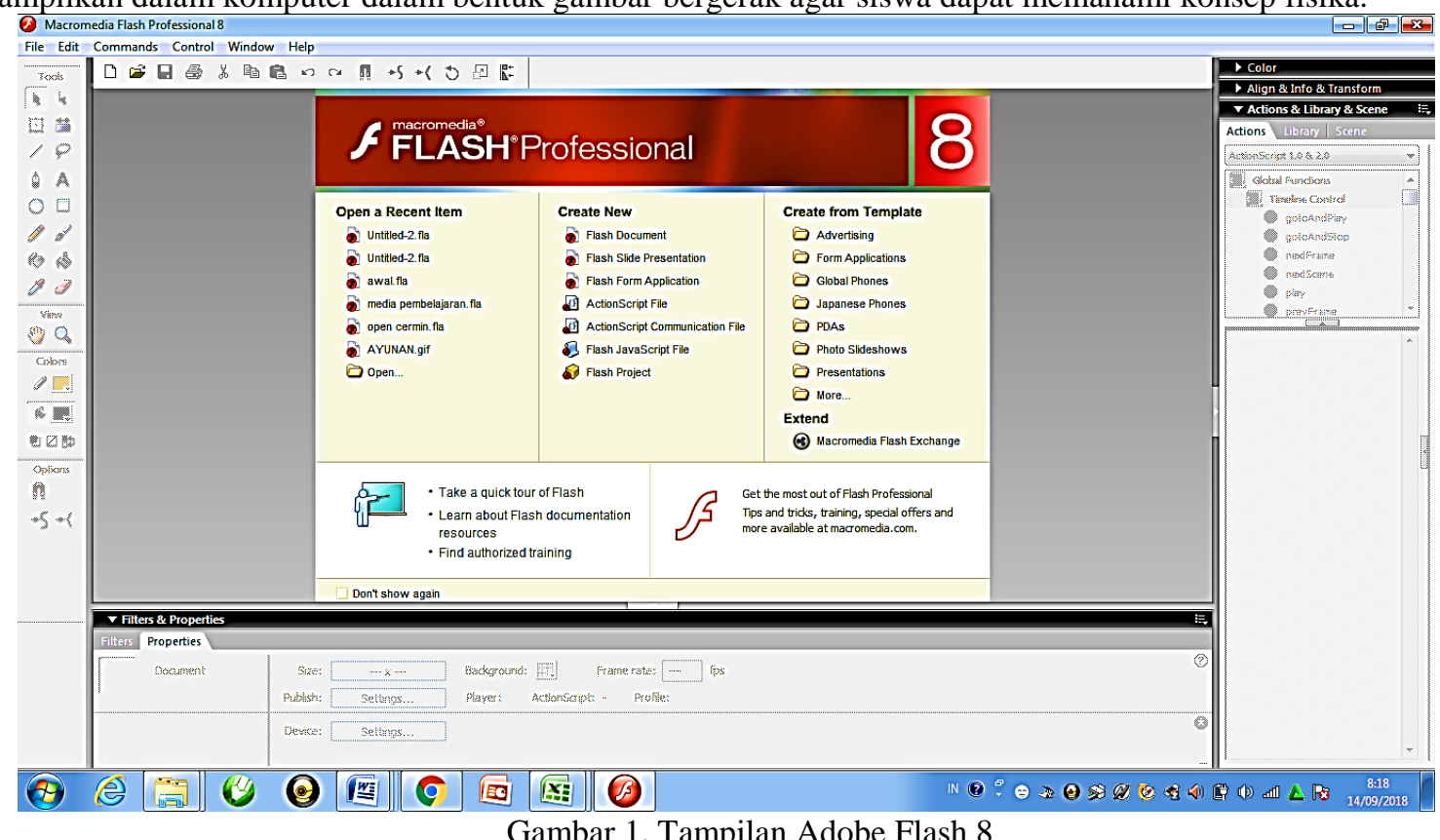

Melalui animasi ini siswa diharapkan dapat melakukan penyelidikan tentang karakteristik usaha dan energi. Animasi pada pembelajaran ini dibuat dengan program Macromedia Flash 8. Macromedia Flash 8 merupakan aplikasi interaktif yang memiliki beberapa kelebihan antara lain format grafis berbasis vektor, kapasitas file hasil yang kecil, memiliki kemampuan mengatur interaktivitas program, memiliki kelengkapan fasilitas dalam melakukan desain. 
Jurnal Qua Teknika, Vol. 8 No. 2 September 2018

p-ISSN: 2088-2424; e-ISSN: 2527-3892

Fakultas Teknik Universitas Islam Balitar, Blitar

Http://qua.unisbablitar.ejournal.web.id; Email; quateknika@Gmail.com

Hazairin Nikmatul L, Deddy Setyawan, Chosinawarotin. 2018. Rancang Bangun Media Animasi Pictorial Riddle sebagai Media Pembelajaran Fisika Bangunan Mahasiswa Teknik Sipil

Jurnal Qua Teknika, (2018), 8(2) : 53-61

\section{Pictorial Riddle}

Menurut Moh. Amin (1979:27), pendekatan dengan menggunakan Pictorial Riddle adalah salah satu teknik/metode untuk mengembangkan motivasi dan ketertarikan siswa di dalam diskusi kelompok kecil maupun besar. Gambar peraga, atau situasi yang sesungguhnya dapat digunakan untuk meningkatkan cara berpikir kritis dan kreatif siswa. Masih menurut Moh. Amin (1979:27), dalam membuat rancangan (desain) suatu riddle, guru harus mengikuti langkah-langkah sebagai berikut, yaitu memilih beberapa konsep atau prinsip yang akan diajarkan atau didiskusikan, melukis suatu gambar, menunjukkan suatu ilustrasi atau menggunakan potret (gambar) yang menunjukkan konsep, proses, atau situasi, suatu prosedur bergantian adalah untuk menunjukkan sesuatu yang tidak sewajarnya, dan kemudian meminta siswa untuk mencari dan menemukan mana yang salah dengan riddle tersebut, membuat pertanyaan-pertanyaan berbentuk "divergen" yang berorientasikan pada proses dan berkaitan dengan riddle (gambar dan sebagainya) yang akan membantu siswa memperoleh pengertian tentang konsep atau prinsip apakah yang terlibat di dalamnya. Sebagai contoh dari riddle tersebut, ada dua buah gambar yang disajikan, misalkan gambar A dan gambar B. Gambar A menampilkan sebuah benda sebelum terjadi peristiwa. Gambar B menunjukkan benda setelah melewati serangkaian peristiwa, sehingga mengalami perubahan bentuk. Mahasiswa kemudian diminta untuk mengidentifikasi peristiwa yang terjadi, dan faktorfaktor yang menyebabkan benda tersebut hingga mengalami perubahan bentuk. Yang harus diperhatikan dalam menyajikan suatu Pictorial Riddle kepada mahasiswa, hendaknya ditunjukkan hal-hal yang perlu diperhatikan, yaitu apa yang harus dicari pada Pictorial itu, sehingga harus mengerti bagaimana mempelajarinya, serta bagaimana menilai Pictorial.

\section{METODE PENELITIAN}

Perancangan dan pembuatan media pembelajaran, dilakukan setelah pengamatan lapangan sebelumnya. Adapun Desain penelitian sebagai berikut :

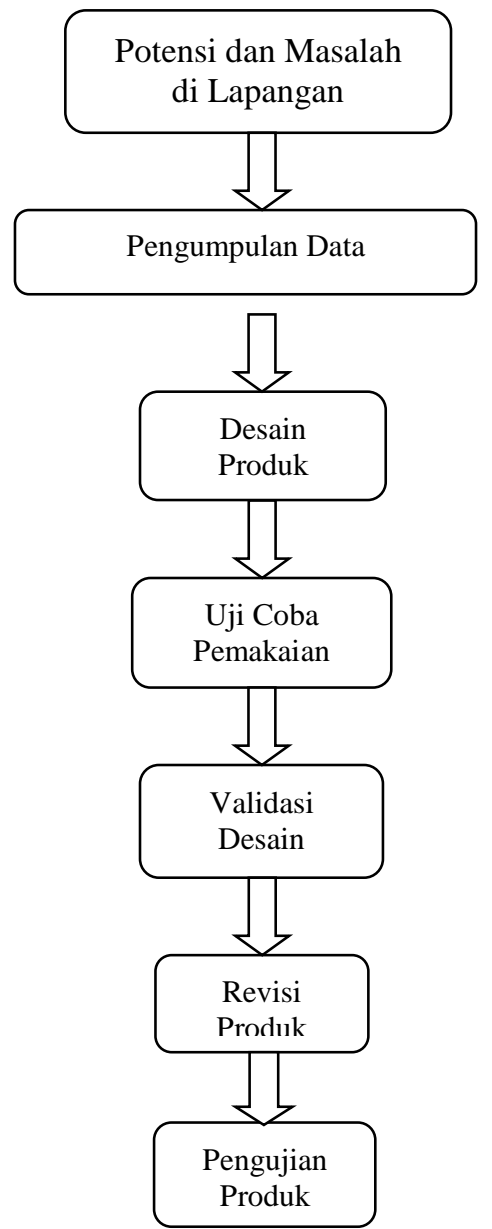

Gambar 2. Desain Penelitian 
Jurnal Qua Teknika, Vol. 8 No. 2 September 2018

p-ISSN: 2088-2424; e-ISSN: 2527-3892

Fakultas Teknik Universitas Islam Balitar, Blitar

Http://qua.unisbablitar.ejournal.web.id; Email; quateknika@Gmail.com

Hazairin Nikmatul L, Deddy Setyawan, Chosinawarotin. 2018. Rancang Bangun Media Animasi Pictorial Riddle sebagai Media Pembelajaran Fisika Bangunan Mahasiswa Teknik Sipil

Jurnal Qua Teknika, (2018), 8(2) : 53-61

\section{Desain Media}

Tampilan dasar dari program ini dapat dilihat dalam gambar 3, berupa layer-layer yang berisi nama dari masing-masing halaman. Pada halaman pertama terdapat pilihan menu yang merupakan pilihan dari isi media.

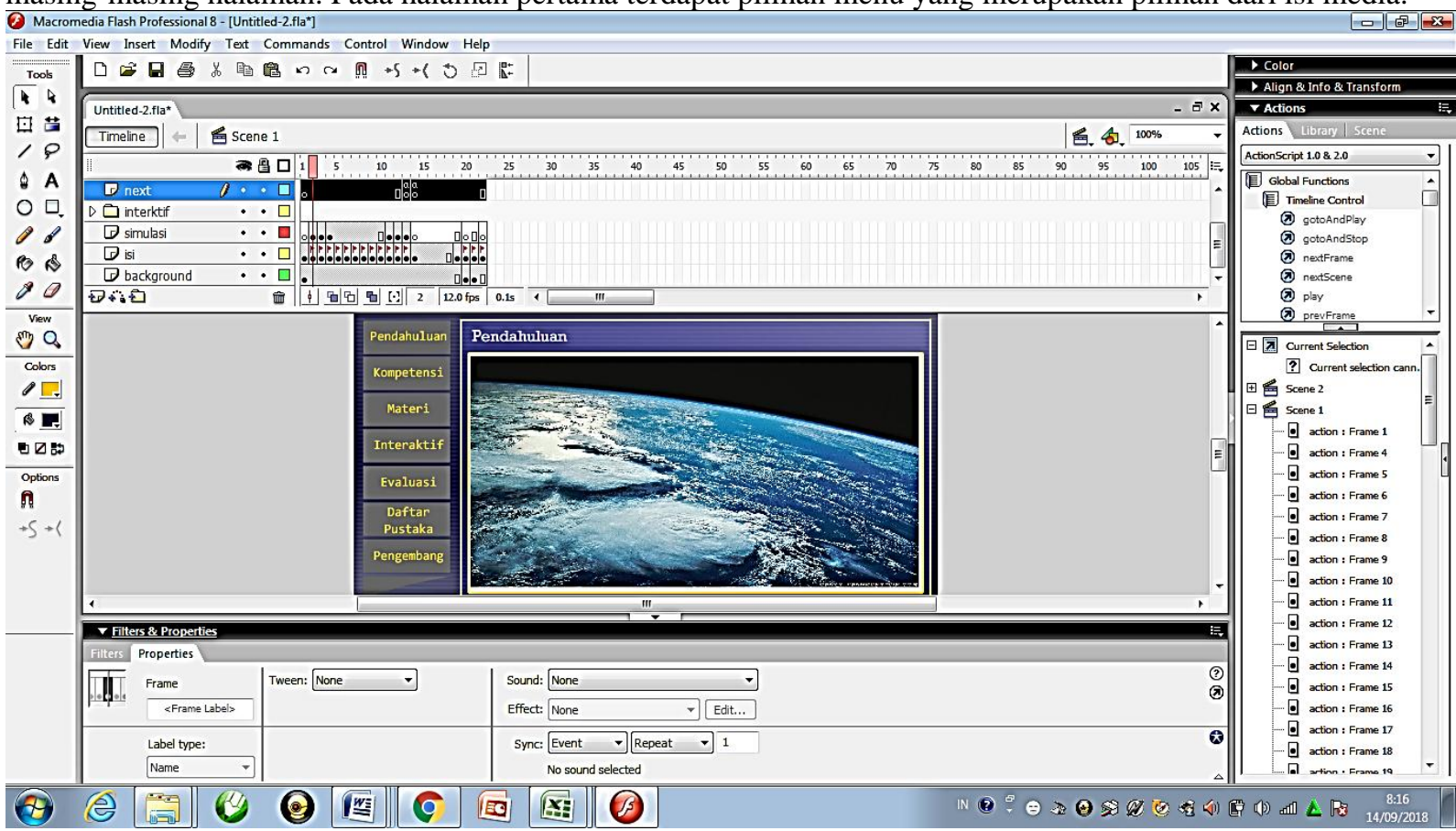

Gambar 3 Tampilan Desain halaman awal

Berikut ini tampilan awal dari media animasi Pictorial Riddle yang siap disajikan

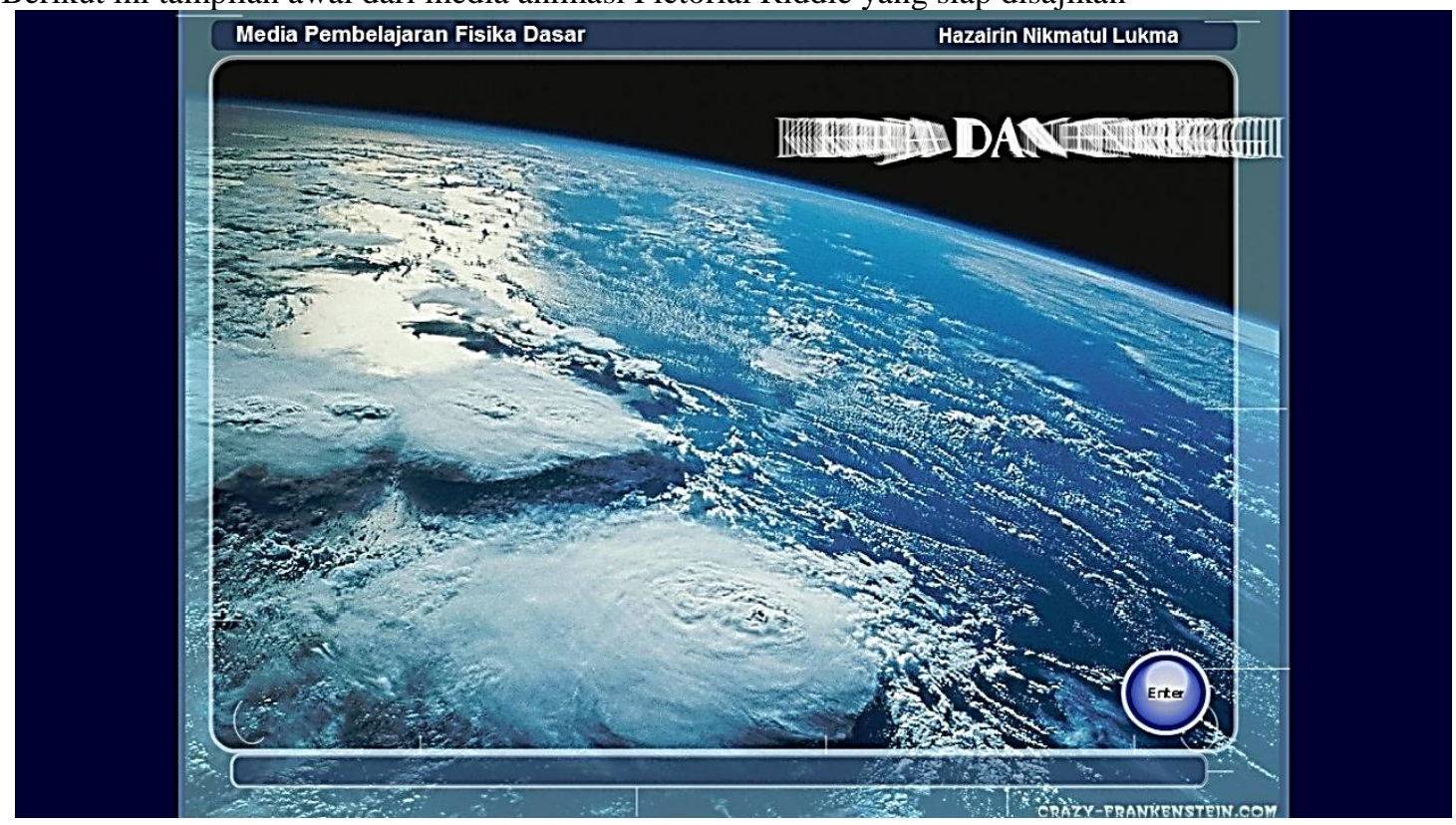

Gambar 4 Halaman Awal Media Pembelajaran

Setiap layer diberikan nama sesuai dengan fungsinya, untuk mempermudah saat pengerjaan. Jadi, misalkan halaman pertama sebagai pembukaan, dapat diberikan nama "halaman depan". Demikian juga untuk halaman selanjutnya, disesuaikan dengan nama-nama layer. 
Jurnal Qua Teknika, Vol. 8 No. 2 September 2018

p-ISSN: 2088-2424; e-ISSN: 2527-3892

Fakultas Teknik Universitas Islam Balitar, Blitar

Http://qua.unisbablitar.ejournal.web.id; Email; quateknika@Gmail.com

Hazairin Nikmatul L, Deddy Setyawan, Chosinawarotin. 2018. Rancang Bangun Media Animasi Pictorial Riddle sebagai Media Pembelajaran Fisika Bangunan Mahasiswa Teknik Sipil Jurnal Qua Teknika, (2018), 8(2) : 53-61

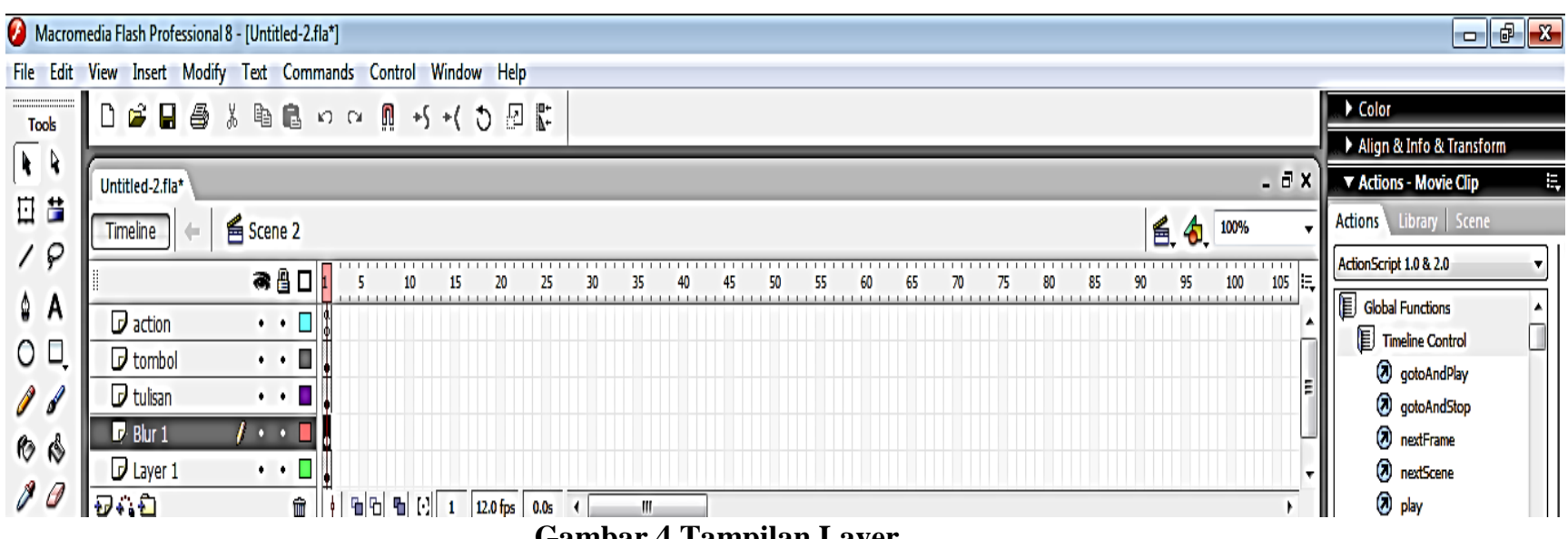

Setiap halaman juga tersedia tombol untuk mempermudah navigasi. Klik tombol pada stage seperti pada tampilan berikut ini.
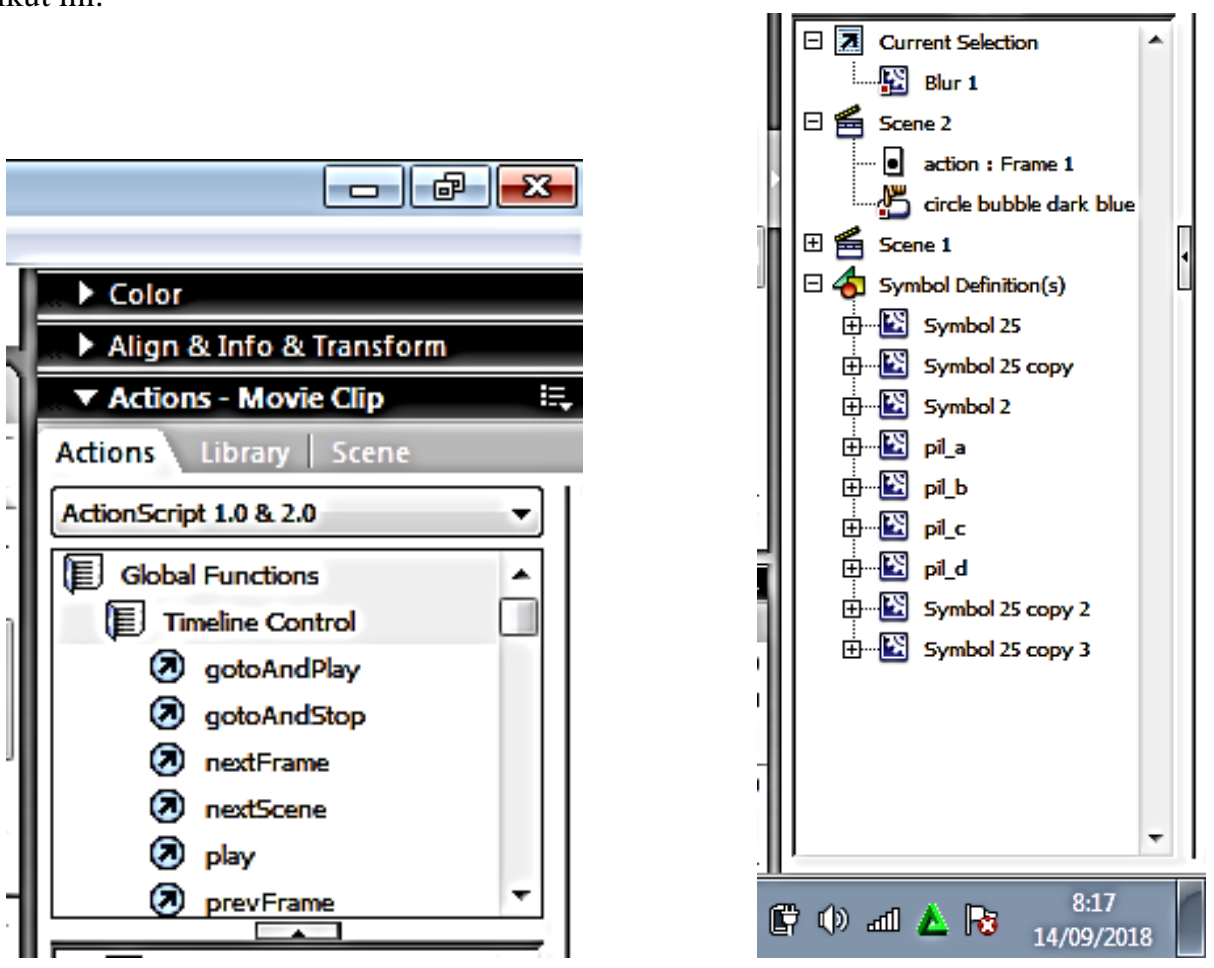

Gambar 5 Tampilan Stage

\section{Tampilan Media}

Pada tampilan media juga disediakan halaman evaluasi, untuk menguji sejauh mana pemahaman dari media yang telah disampaikan. Pada kolom nama, harus diisi terlebih dahulu namanya. Jika tidak maka tidak dapat diproses lebih lanjut. Soal hanya berjumlah 5 butir saja, hanya sebagai refleksi materi saja. Setelah nama diisi maka tombol mulai bisa diklik untuk menuju halaman selanjutnya.

Setelah dilakukan evaluasi, maka akan ditampilkan hasil sesuai dengan nama yang dimasukkan tadi. Tertulis ada berapa banyak nomor yang benar, dan ditunjukkan pula nomor berapa saja yang salah saat memasukkan jawaban. Hasil dari penskoran juga ditampilkan. Misalkan nama yang dimasukkan tadi adalah Jono, maka akan tampil nama Jono dan rincian penskorannya. 
Jurnal Qua Teknika, Vol. 8 No. 2 September 2018

p-ISSN: 2088-2424; e-ISSN: 2527-3892

Fakultas Teknik Universitas Islam Balitar, Blitar

Http://qua.unisbablitar.ejournal.web.id; Email; quateknika@Gmail.com

Hazairin Nikmatul L, Deddy Setyawan, Chosinawarotin. 2018. Rancang Bangun Media Animasi Pictorial Riddle sebagai Media Pembelajaran Fisika Bangunan Mahasiswa Teknik Sipil Jurnal Qua Teknika, (2018), 8(2) : 53-61

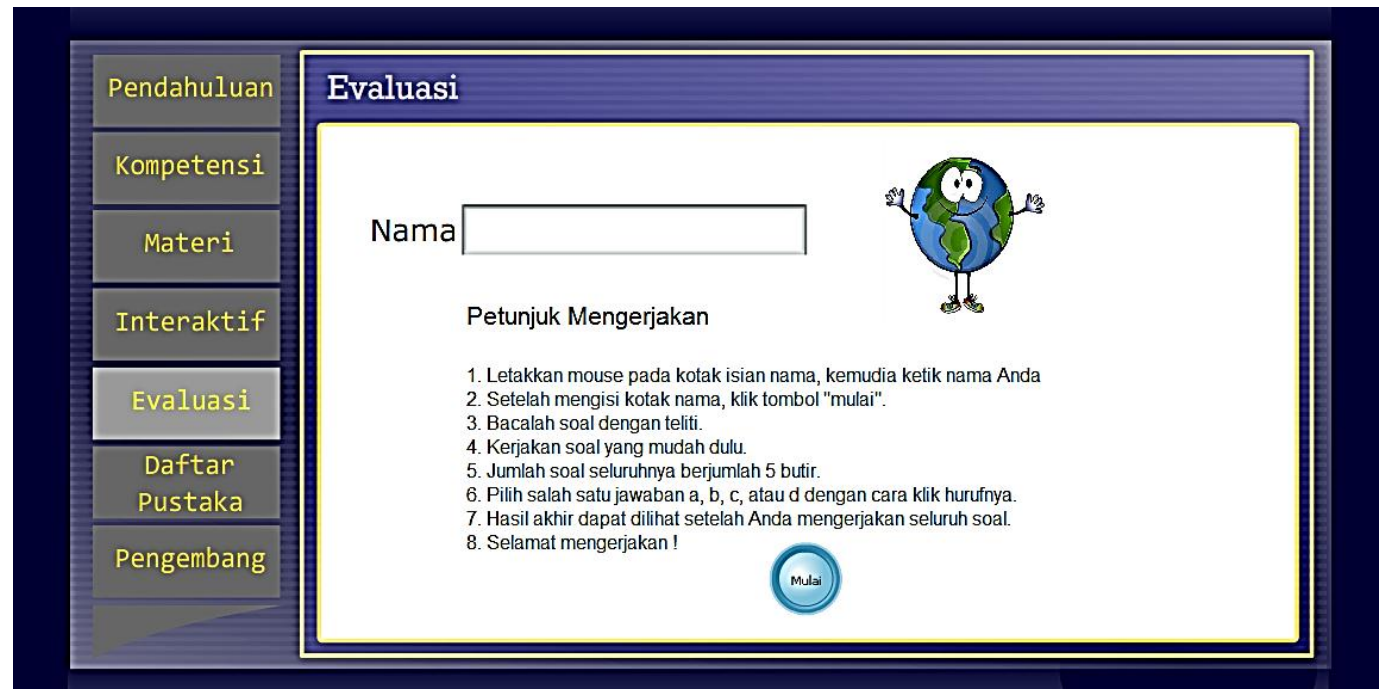

Gambar 6 Tampilan Halaman Evaluasi

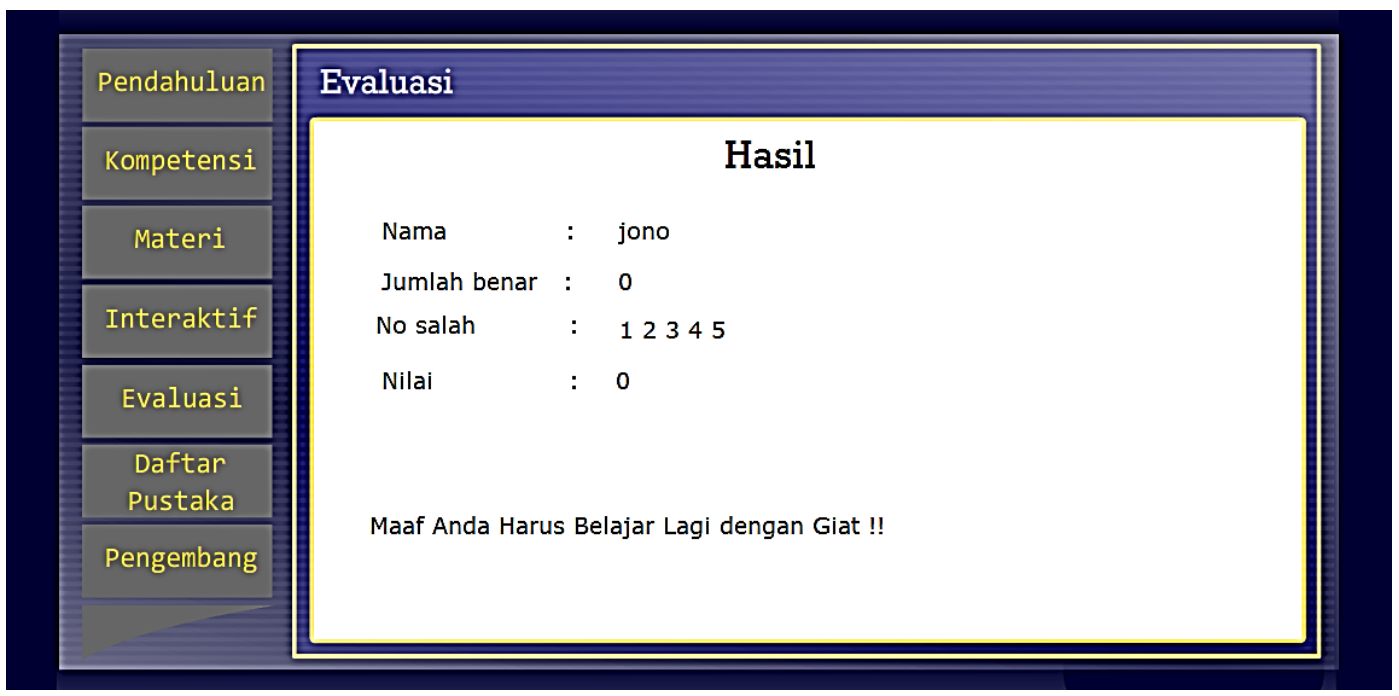

Gambar 7 Tampilan Halaman Hasil

\section{Pengambilan Data}

Variabel Penelitian ini meliputi variabel bebas yaitu metode pictorial riddle dan variabel terikat yaitu penguasaan konsep Fisika, dengan desain penelitian menggunakan One-Group Pretest- Posttest Design:

\section{$\begin{array}{lll}\mathbf{O}_{1} & \mathrm{X} & \mathrm{O}_{2}\end{array}$}

Keterangan :

$\mathrm{O}_{1}=$ Pemahaman materi fisika bangunan mahasiswa sebelum pembelajaran pictorial riddle

$\mathrm{X}=$ Perlakuan kepada mahasiswa yaitu pembelajaran pictorial riddle

$\mathrm{O}_{2}=$ Pemahaman materi fisika bangunan mahasiswa setelah pembelajaran pictorial riddle

\section{HASIL DAN PEMBAHASAN}

Pengujian dilakukan dua kali yaitu pada pertemuan pertama dan pada pertemuan kedua. Hasil dari pengujian pertama digambarkan grafik berikut ini. 
Jurnal Qua Teknika, Vol. 8 No. 2 September 2018

p-ISSN: 2088-2424; e-ISSN: 2527-3892

Fakultas Teknik Universitas Islam Balitar, Blitar

Http://qua.unisbablitar.ejournal.web.id; Email; quateknika@ Gmail.com

Hazairin Nikmatul L, Deddy Setyawan, Chosinawarotin. 2018. Rancang Bangun Media Animasi Pictorial Riddle sebagai Media Pembelajaran Fisika Bangunan Mahasiswa Teknik Sipil Jurnal Qua Teknika, (2018), 8(2) : 53-61

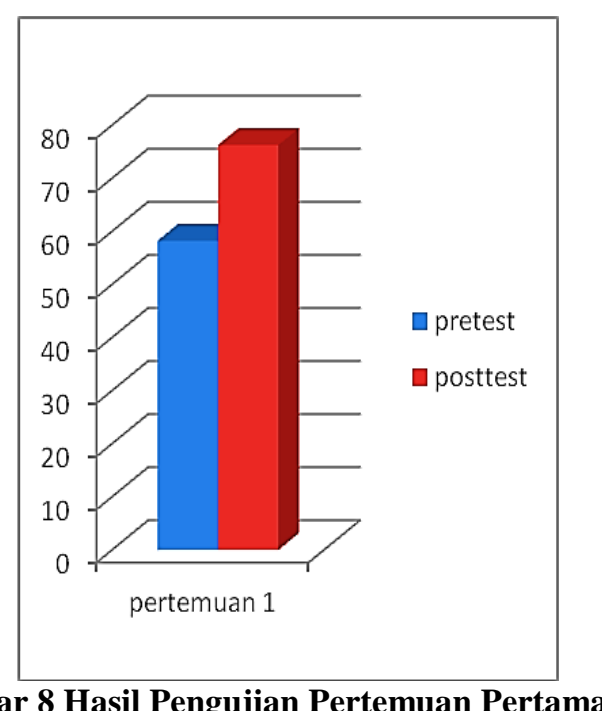

Terlihat bahwa terjadi kenaikan antara hasil pretes dan postest. Pada pengujian pertemuan kedua, dilakukan pretest dan posttest, dan diperoleh hasil seperti yang digambarkan pada grafik di bawah ini.

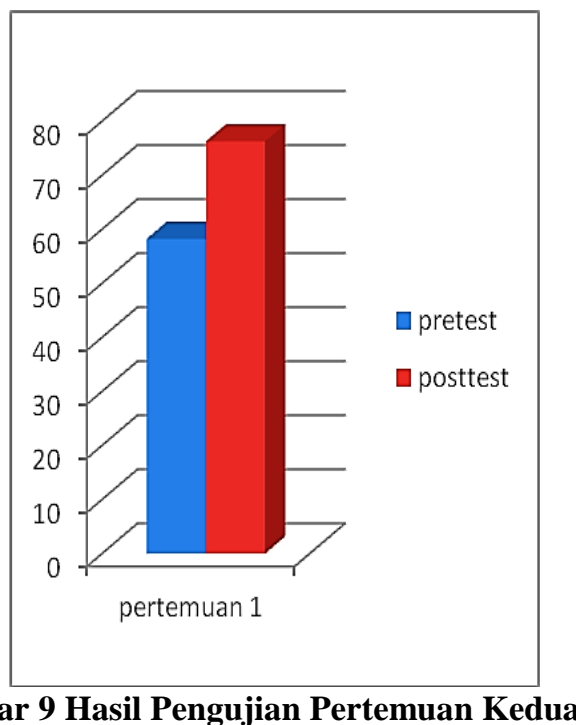

Terlihat bahwa terjadi kenaikan juga antara hasil pretes dan postest. Dari kedua hasil pengujian tersebut kemudian dihitung perolehan n-gain nya, seperti yang disajikan pada grafik di gambar 10 .

Hasil pengujian menunjukkan ada perbedaan pada tingkat penguasaan konsep Fisika Dasar sebelum dan sesudah pembelajaran dengan metode Pictorial Riddle. Sebelum mahasiswa mendapatkan pembelajaran menggunakan media Pictorial Riddle, terlebih dahulu diberikan pretest, untuk menguji sejauh mana pemahaman mereka terhadap materi. Selanjutnya, setelah pembelajaran menggunakan media dilaksanakan, tes kembali dilakukan, dalam bentuk postest.

Metode Pictorial Riddle merupakan salah satu alternatif dalam metode pembelajaran yang dapat meningkatkan motivasi belajar, dimana metode ini menuntut mahasiswa untuk berpikir kritis sehingga mereka mampu mengeluarkan inisiatifnya sendiri. Selain itu, metode ini juga mampu mendorong mahasiswa untuk dapat berpikir intuitif dan merumuskan hipotesisnya sendiri. Karena disajikan dalam bentuk gambar, maka materi akan terekam lebih lama dalam memori mereka. 


\section{SIMPULAN}

Dari hasil pengujian diperoleh bahwa rata-rata nilai saat dilakukan pretest untuk pertemuan pertama adalah sebesar 58,21. Dan setelah diberikan pembelajaran, kemudian dilakukan posttest, diperoleh nilai rata-rata sebesar 76,27 Untuk pertemuan kedua, diperoleh hasil pretest sebesar 64,05 dan hasil posttest sebesar 77,12.

Dari grafik di atas terlihat bahwa terjadi kenaikan rata-rata nilai fisika dasar mahasiswa, antara sebelum diberikan media, dan setelah diberikan media pembelajaran. Adapun untuk perolehan N-gain, menunjukkan angka 0,4 untuk pertemuan pertama, dan 0,35 untuk pertemuan kedua. Hal ini mengandung maksud bahwa penguasaan konsep mahasiswa terhadap materi berada pada kategori sedang. Metode Pictorial Riddle mampu mendorong mahasiswa untuk dapat berpikir intuitif dan merumuskan hipotesisnya sendiri. Karena disajikan dalam bentuk gambar, maka materi akan terekam lebih lama dalam memori mereka.

\section{REFERENSI}

[1] Azhar Arsyad. 2002. Media Pembelajaran. Jakarta : PT. Raja Grafindo Persada

[2] Benito, RM, Camara, ME, Losada, JC, Arranz, FJ, dan Seidel, L. 2007. Using Moodle and Flash Animations in an Interactive Learning Environment for Introductory Physics in Engineering. http//:www.wseas.us/e-library/conferences/2007tenerife/papers/572-588.pdf

[3] Dermott, Lilian C. Mc.; Shaffer, Peter S; Rosenquist, Mark L..-------. Physics by Inquiry and Introduction to Physical Science Volume II. Washington : John Willey and Sons Inc

[4] Trianto. 2009. Mendesain Model Pembelajaran Inovatif Progresif. Jakarta : Kencana Prenada Media Group

[5] Popov, Oleg dan Tevel, Irina.------. Developing an Introductory Physics Course in Teacher Education Using Guided Inquiry and Outdoors Approaches. http//:www.outlab.ie/forums/.../popovjbsevol6no120070330_unu_se 306.pdf

[6] Kohl, Patrick B. dan Finkelstein, Noah D..------. Representational Format, Student Choice, and Problem Solving in Physics. http//:www.adsabs.harvard.edu/abs/2005AIPC..790..121K

[7] Sri Anitah. 2007. Modul PLPG Media Pembelajaran. Surakarta : Panitia Sertifikasi Guru Rayon 13

[8] Alfi Zarisa, Saminan. 2017. Penerapan Pembelajaran Inkuiri menggunakan Metode Pictorial Riddle pada Materi Alat-Alat Optik untuk Meningkatkan Kreativitas dan Hasil Belajar Siswa. Jurnal Pendidikan Sains Indonesia, 5 (1), 1-4.

[9] Sitti Awal, Ahmad Yani, Bunga Dara Amin. 2016. Peranan Pictorial Riddle terhadap Penguasaan Konsep Fisika pada Siswa SMAN 1 Bontonompo. Jurnal Pendidikan Fisika, 4 (2), 249 - 266

[10] Laili Mahmudah, Suparmi, Widha Sunarno. 2014. Pembelajaran Fisika meggunakan Metode Pictorial Riddle dan Problem Solving ditinjau dari Kemampuan Berpikir Kritis dan Kemampuan Analis. Jurnal Inkuiri, 3 (2), 48 - 59 
Hazairin Nikmatul L, Deddy Setyawan, Chosinawarotin. 2018. Rancang Bangun Media Animasi Pictorial Riddle sebagai Media Pembelajaran Fisika Bangunan Mahasiswa Teknik Sipil Jurnal Qua Teknika, (2018), 8(2) : 53-61

[11] Siti Masfuah. 2016. Pictorial Riddle melalui Pembelajaran ARCS untuk meningkatkan Kemampuan Pemecahan Masalah dan Motivasi Berprestasi Siswa. Jurnal Konseling Gusjigang, 2 (1), $104-110$.

[12] Siti Masfuah. 2016. Pictorial Riddle melalui Pembelajaran ARCS untuk meningkatkan Kemampuan Pemecahan Masalah dan Motivasi Berprestasi Siswa. Jurnal Konseling Gusjigang, 2 (1), $104-110$.

[13] Lori A Smolleck and Jacillyn Todd. 2017. The Effect of Science in Motion on Self Efficacy Beliefs Regarding Teaching Science As Inquiry. International Journal of Applied Research, 3 (1), 413 - 425.

[14]. Yusuf, Muri. 2013. Metode Penelitian Kuantitatif, Kualitatif, dan Penelitian Gabungan. Jakarta : Kencana Prenadamedia Group, 198- 255.

[15] Yaumi, Muhammad. 2017. Media dan Teknologi Pembelajaran. Jakarta : Kencana Prenadamedia Group, 129- 142

[16] Suryani, Nunuk; Achmad Setiawan; Aditin Putria. 2018. Media Pembelajaran Inovatif dan Pengembangannya. Bandung : PT Remaja Rosdakarya, $47-108$

[17] Trianto. 2009. Mendesain Model Pembelajaran Inovatif Progresif. Kencana Prenadamedia Group, $71-103$

[18] Sutrisno; Suyadi. 2015. Desain Kurikulum Perguruan Tinggi Mengacu Kerangka Kualifikasi Nasional Indonesia. Bandung : PT Remaja Rosdakarya, 132- 157

[19] Heryanto, Imam; Totok Triwibowo. 2018. Path Analysis menggunakan SPSS dan Excel. Bandung : Penerbit Informatika 